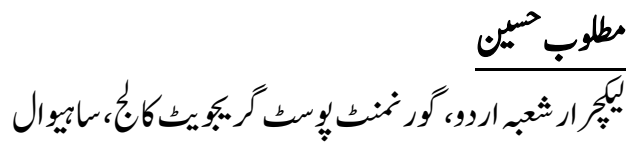

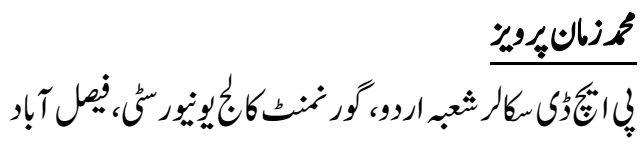

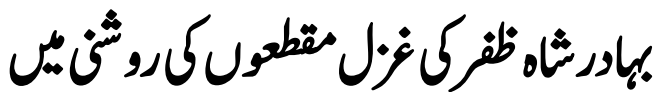

\section{Matloob Hussain}

Lecturer, Department of Urdu, Govt. Post Graduate College, Sahiwal. Muhammad Zaman Parvez

Ph.D Scholar, Department of Urdu, Govt. College University, Faisalabad.

\section{Bahadar Shah Zafar's Ghazal in the light of the articles}

Bahadur Shah Zafar is the most important poet of classical Urdu ghazal. His ghazal reflects the conditions of his time. His life is a practical picture of rise and fall. He had to endure extremes of grief and sorrow in his life. He was the last king of the Mughal dynasty. He was imprisoned and sent to Rangoon as a punishment. He spent the last days of his life in great pain and loneliness. In his ghazals, love, social issues, grief and Sufism are frequently described. His solemns are enriched with meanings. His style of writing is simple and charming. His poetry is also technically impressive. That is why his poetry has been immortalized.

Keywords: Bahadur shah zafar, rise and fall, grief and sorrow, Rangoon, Coneliness, Sufism, solemns.

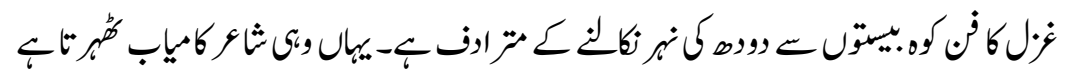

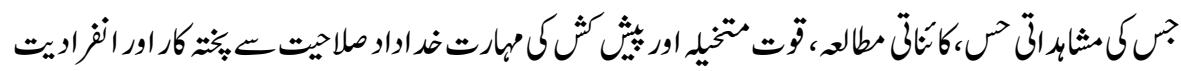

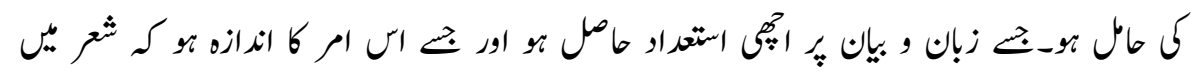

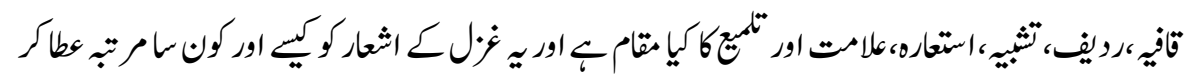

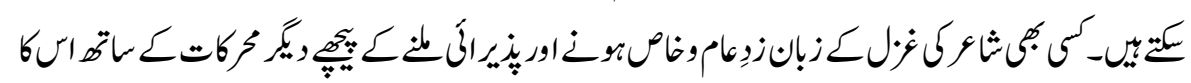




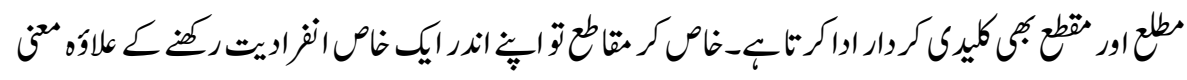

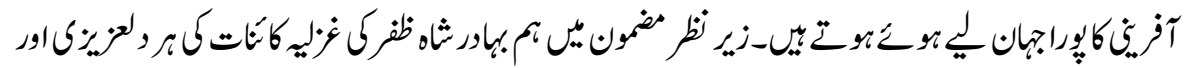

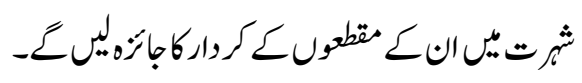

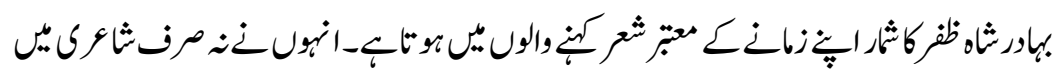

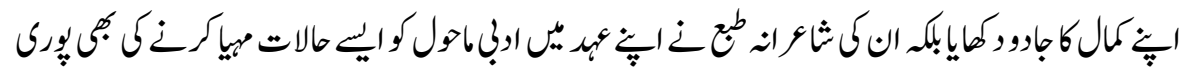

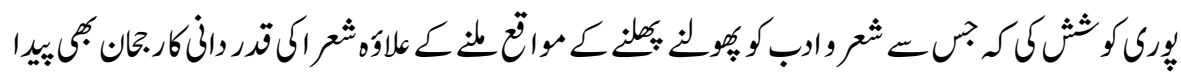

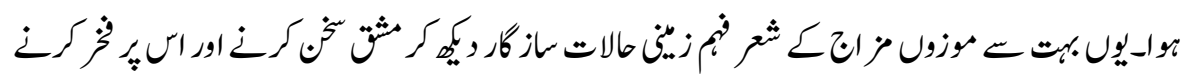

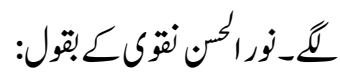

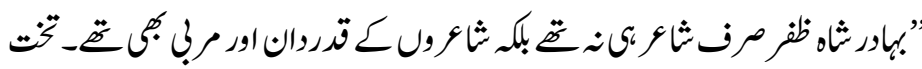

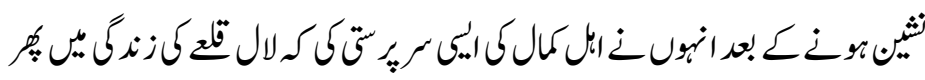

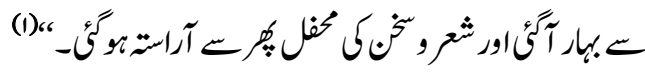

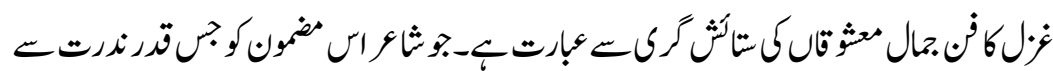

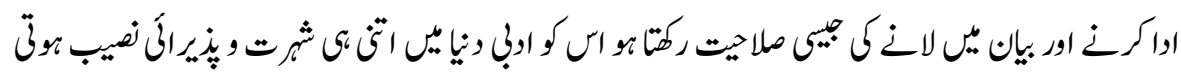

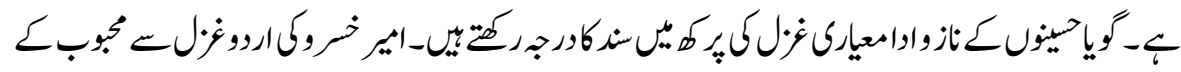

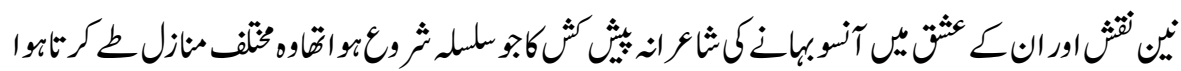

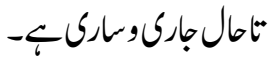

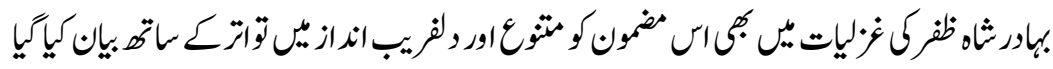

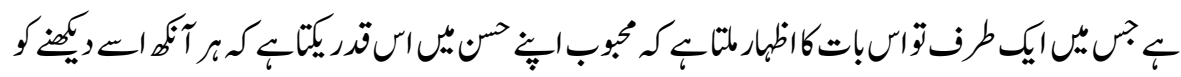

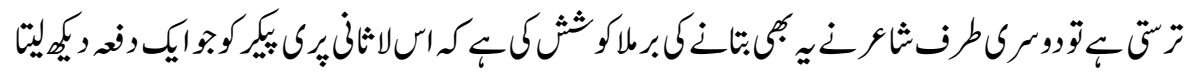

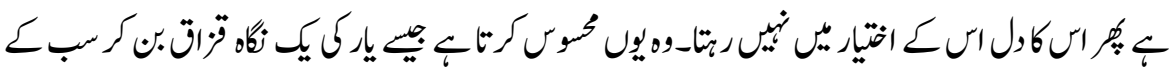

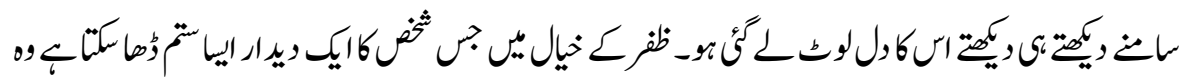

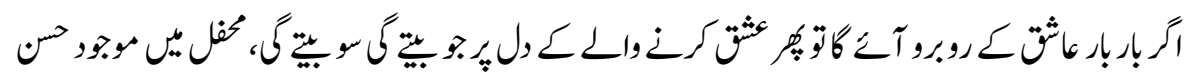

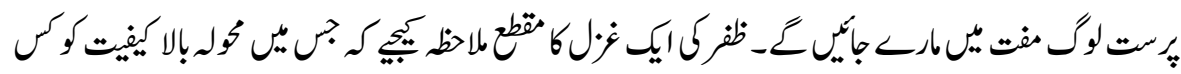




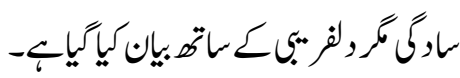

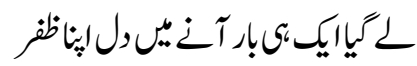

(r) ל

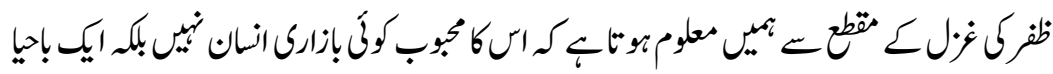

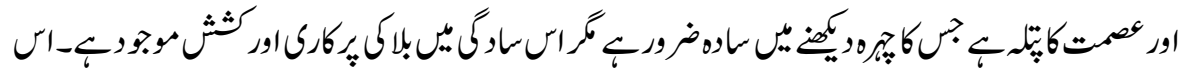

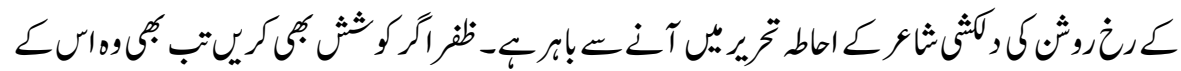

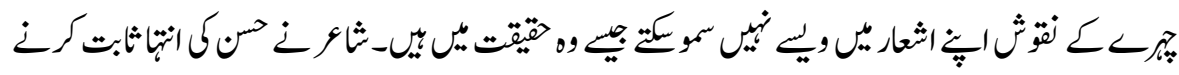

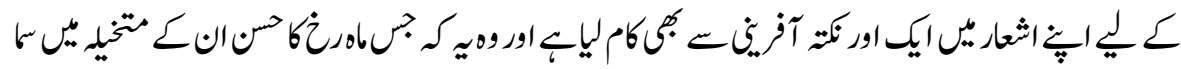

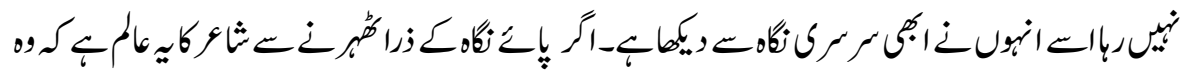

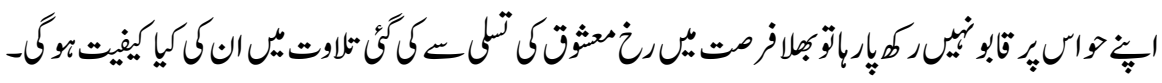

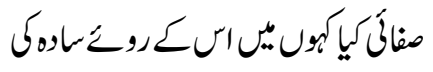

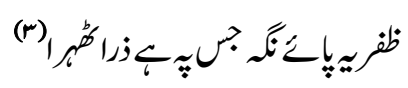

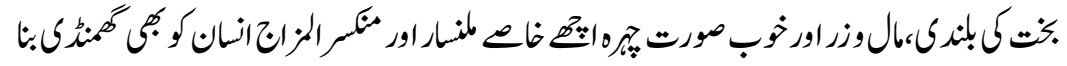

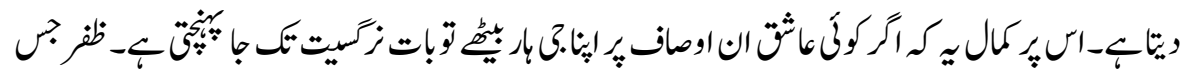

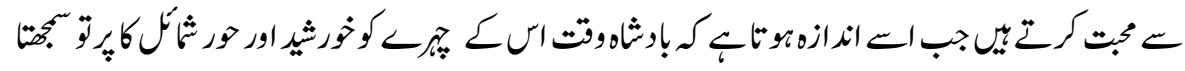

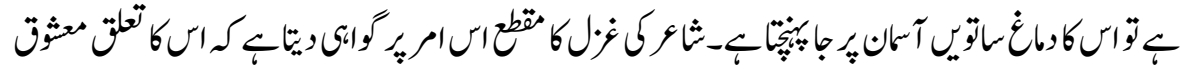

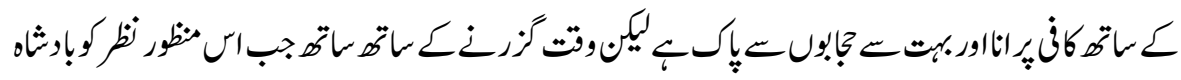

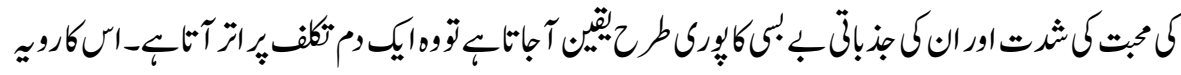

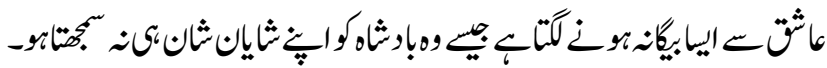

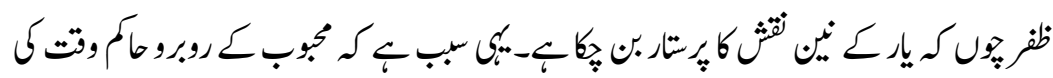

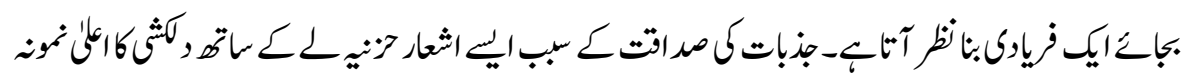

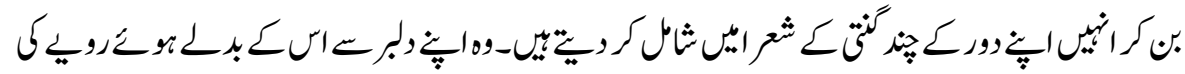




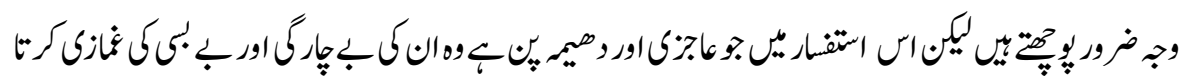

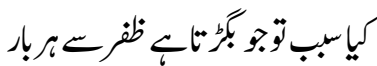

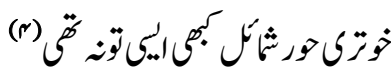

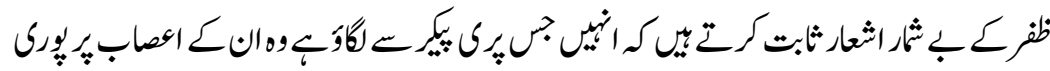

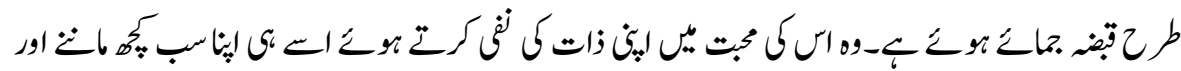

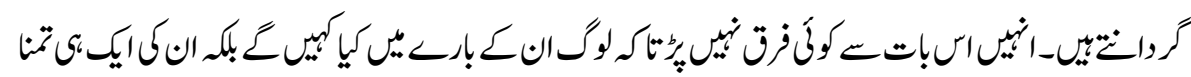

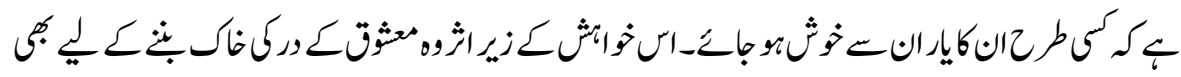

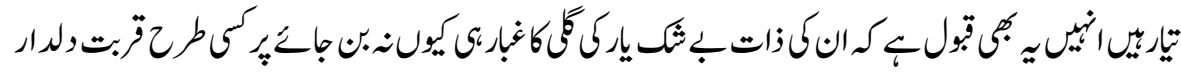

$$
\text { نصيبنوباحخ }
$$

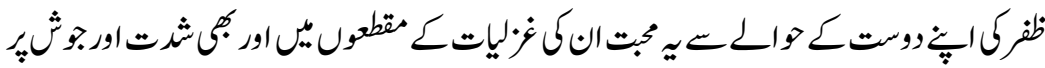

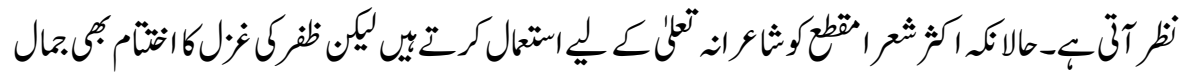

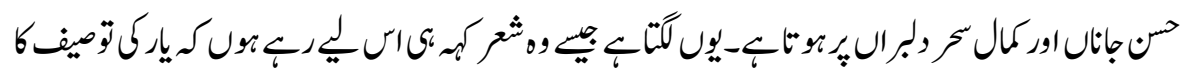

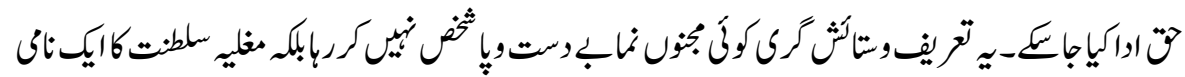

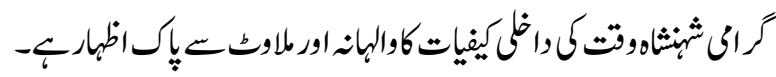

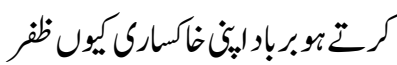

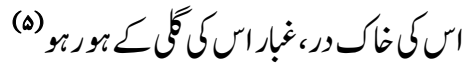

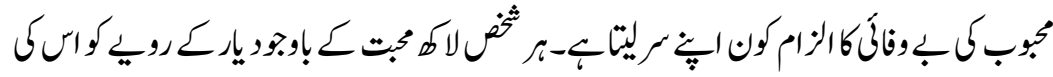

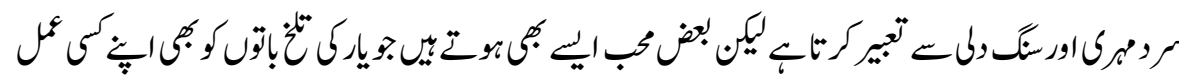

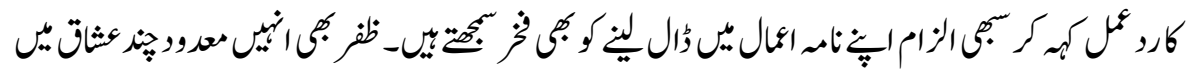

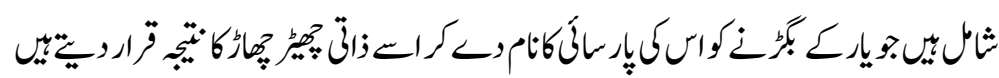

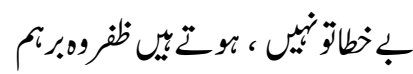

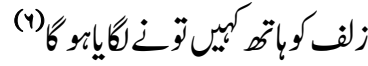


ISSN (Print): 2709-9636 | ISSN (Online): 2709-9644

Volume 2, Issue IV, (October to Decmber 2021)

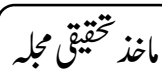

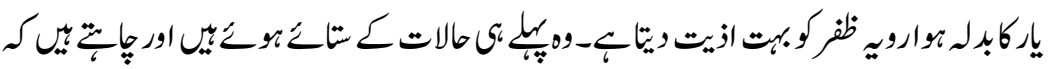

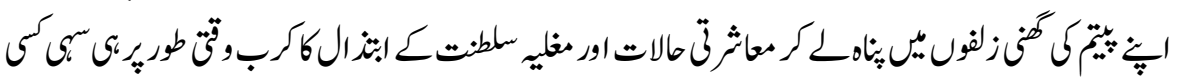

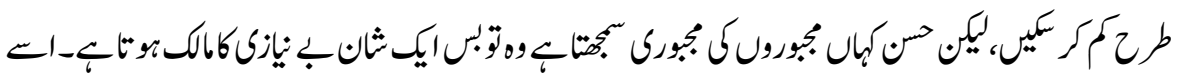

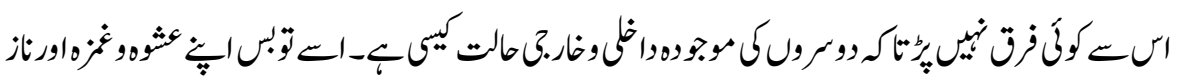

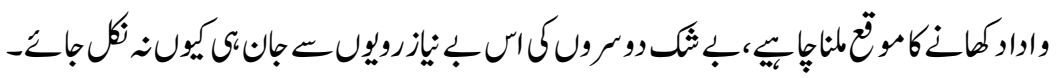

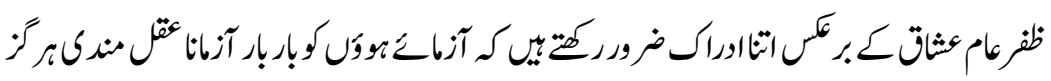

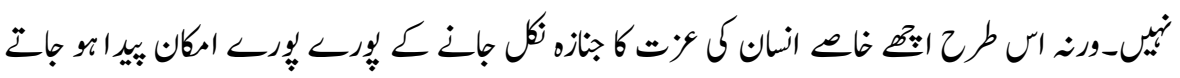

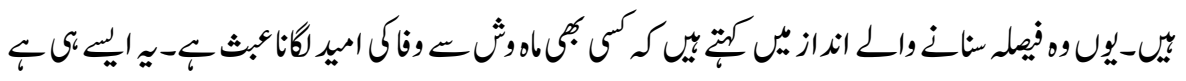

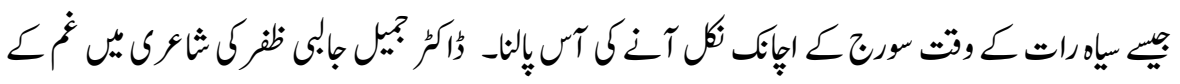

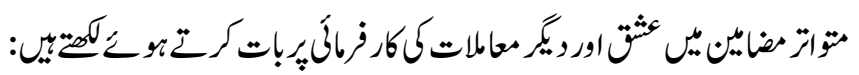

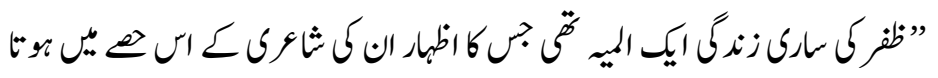

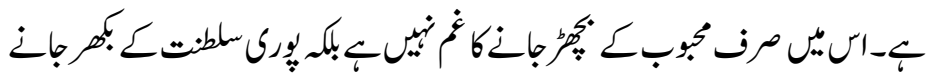

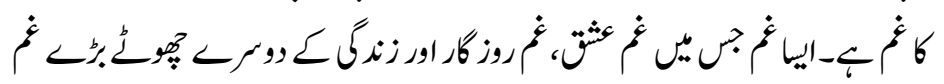

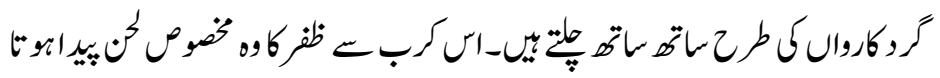

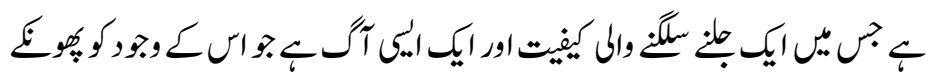

(2)، ")

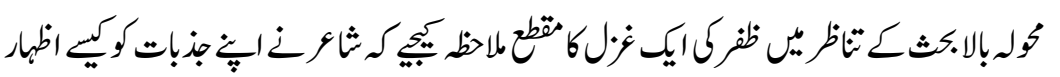

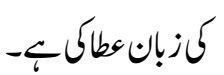

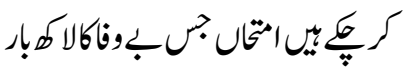

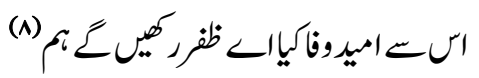

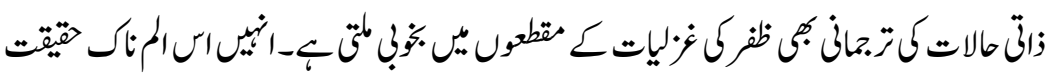

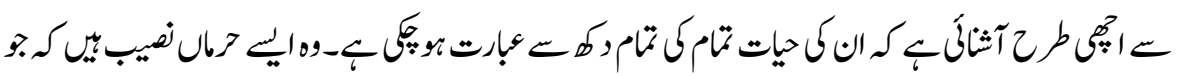

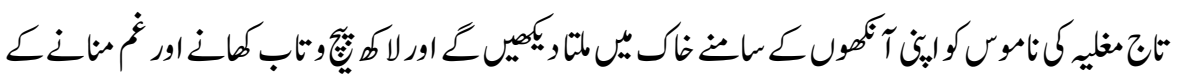

$|0|$ 


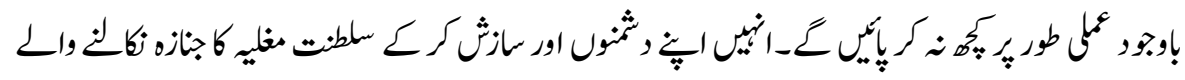

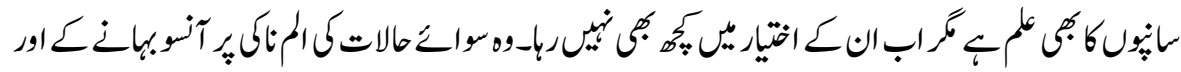

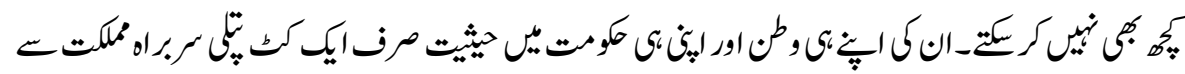

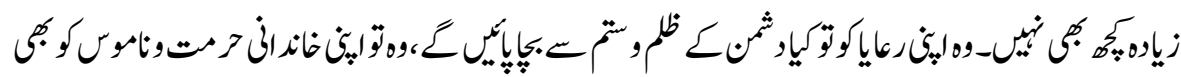

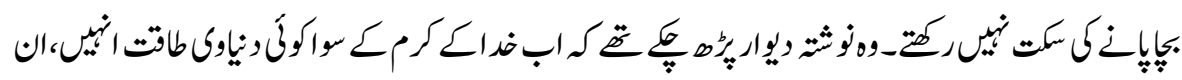

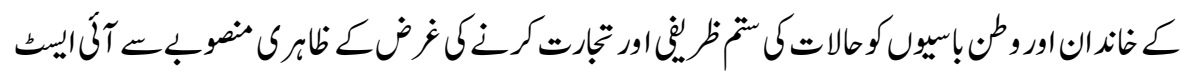

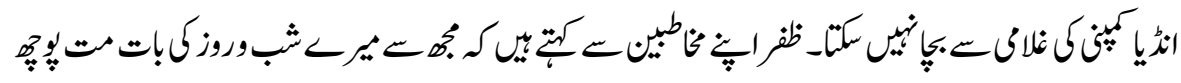

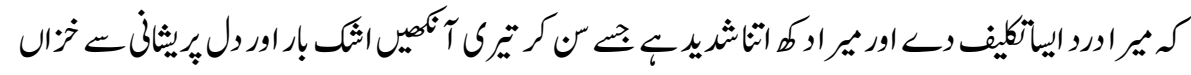

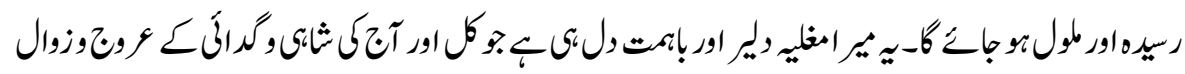

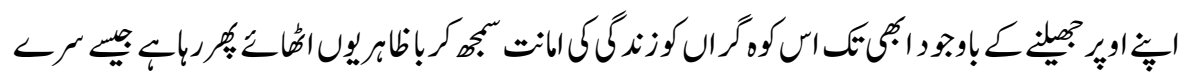

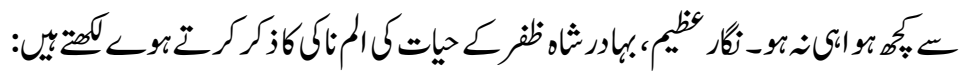

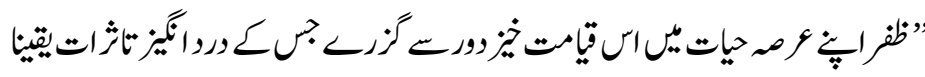

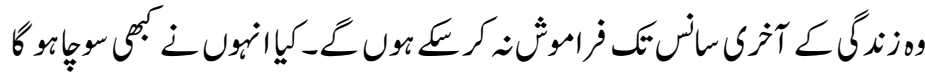

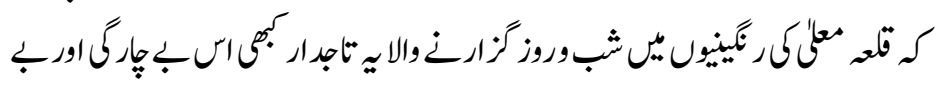

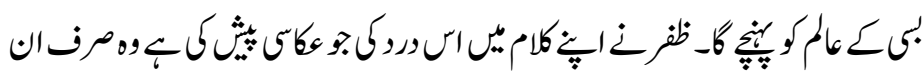

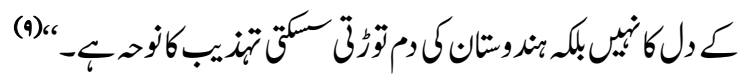

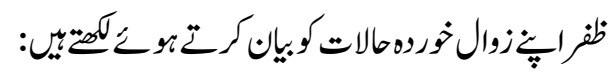

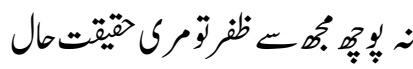

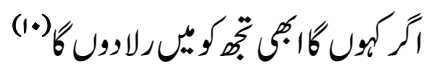

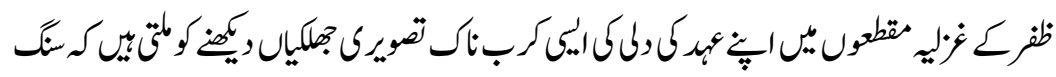

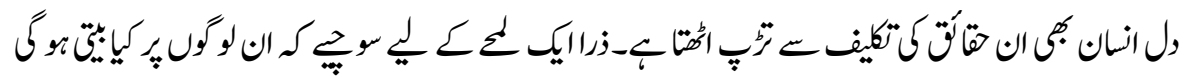

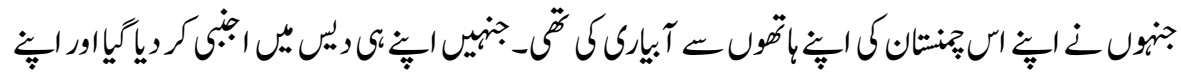

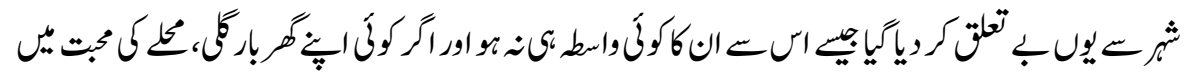




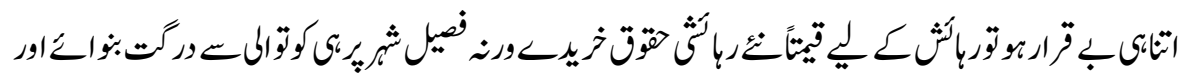
جباتبخ

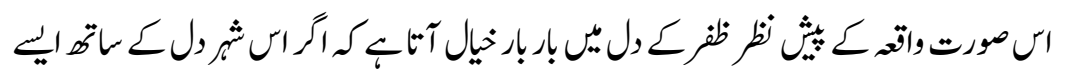

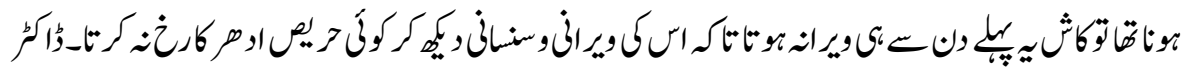

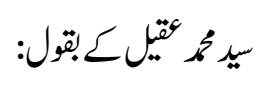

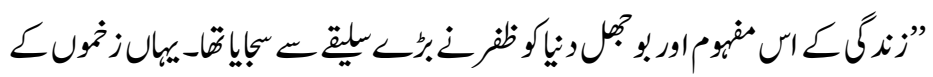

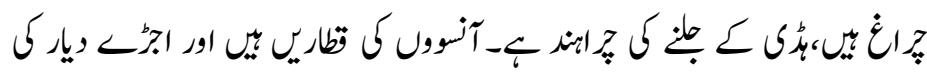

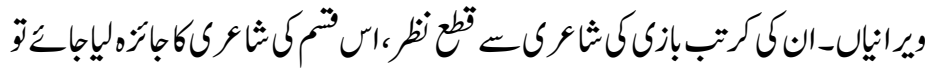

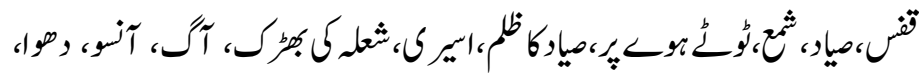

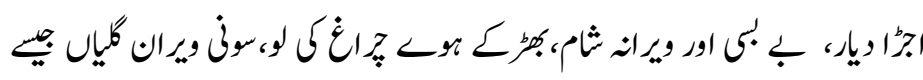

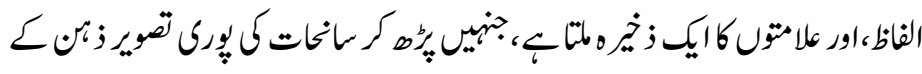

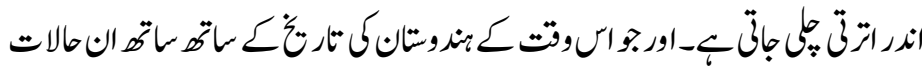

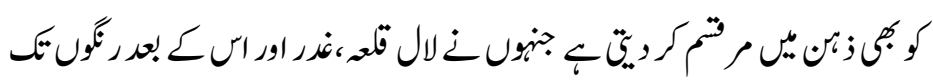

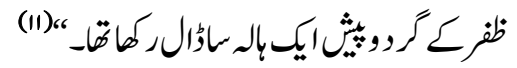

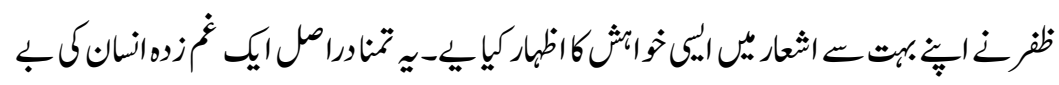

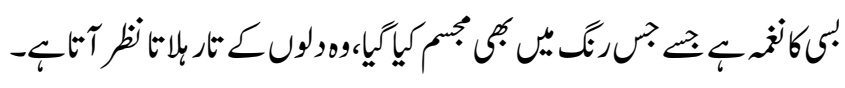

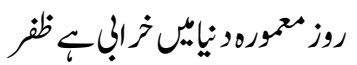

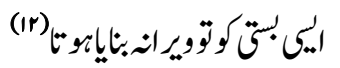

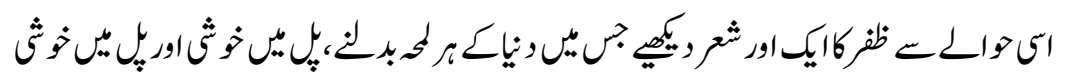

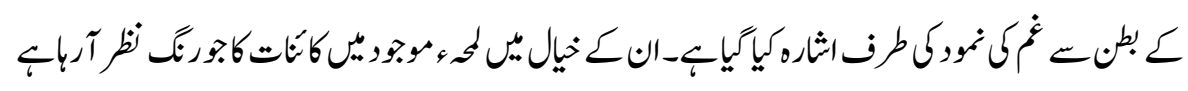

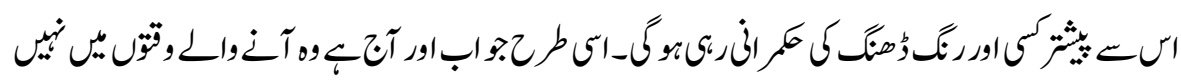

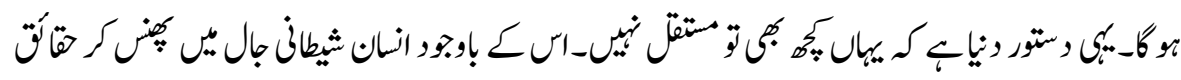

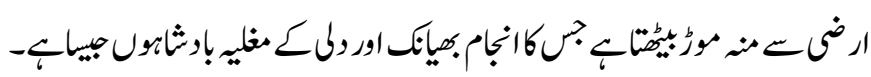




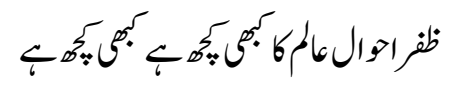

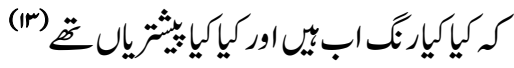

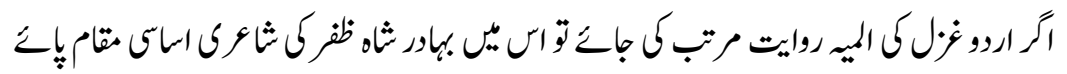

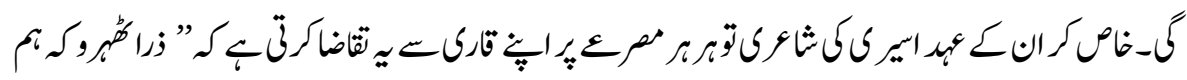

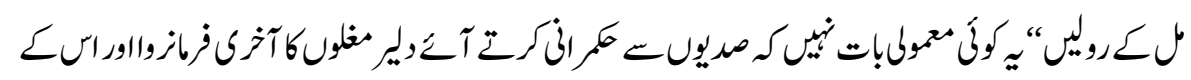

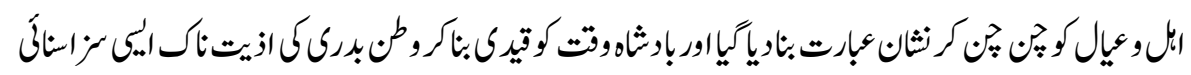

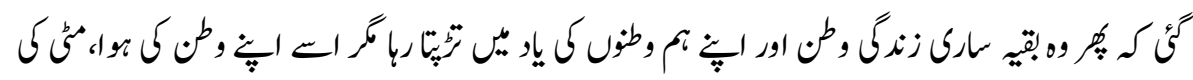

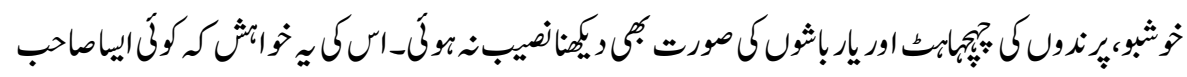

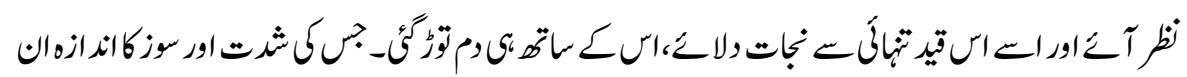

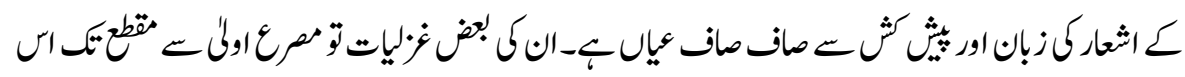

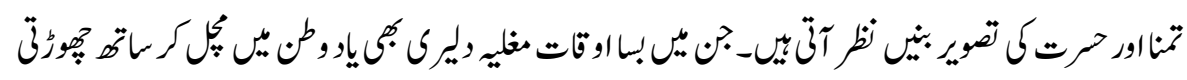

$$
\begin{aligned}
& \text { معلومنوظقب }
\end{aligned}
$$

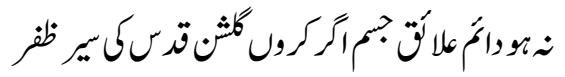

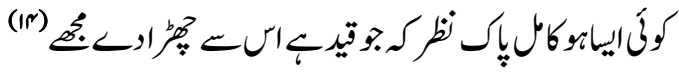

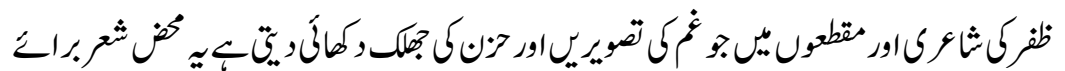

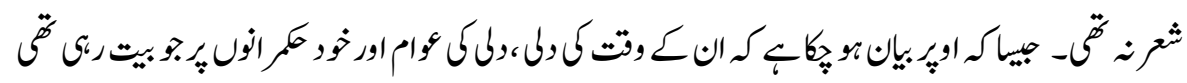

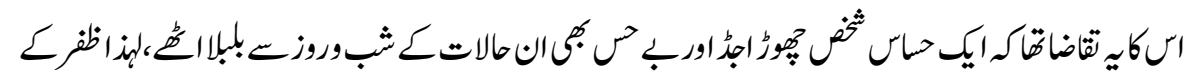

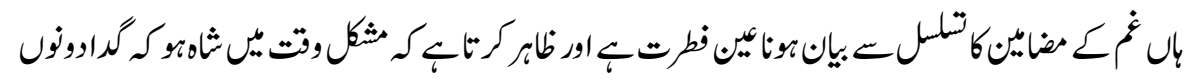

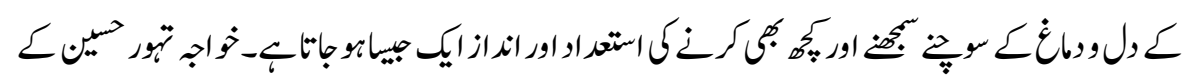

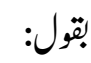

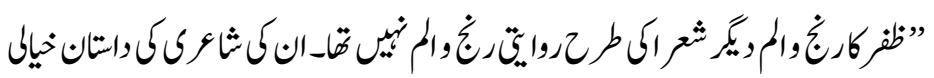

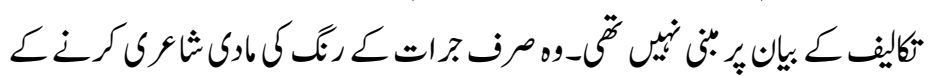

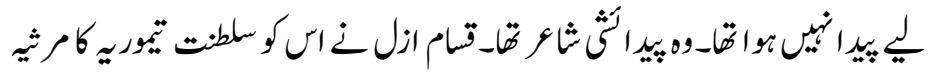




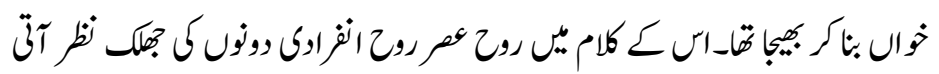

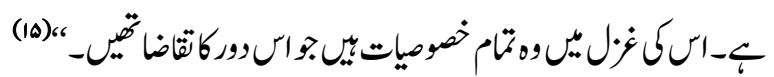

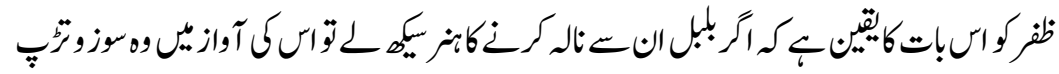

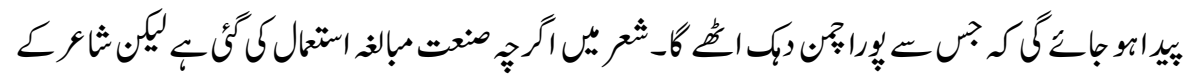

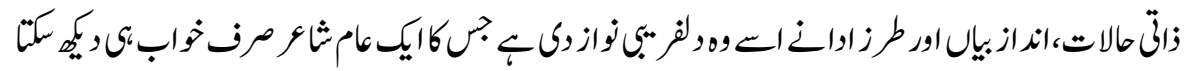

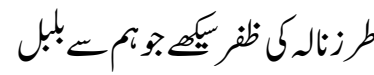

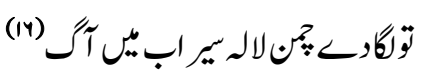

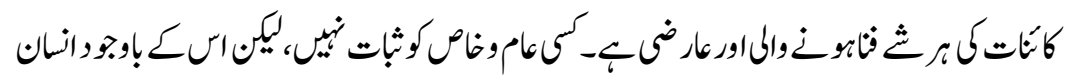

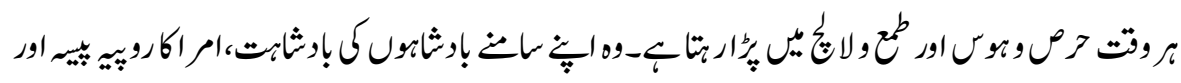

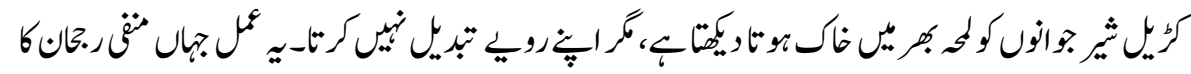

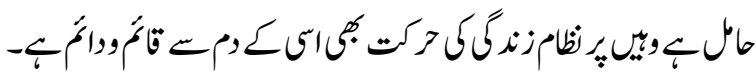

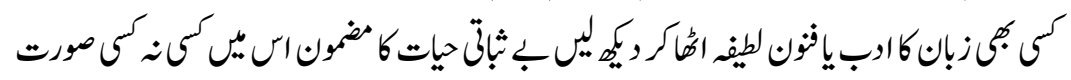

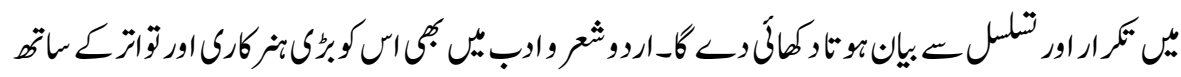

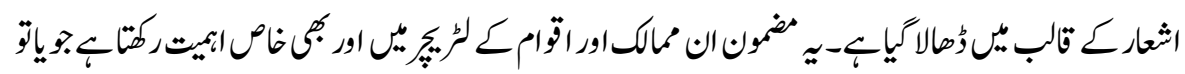

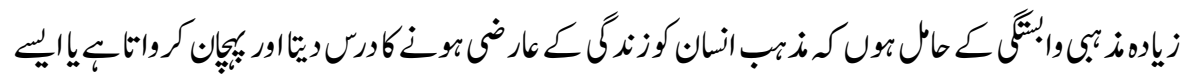

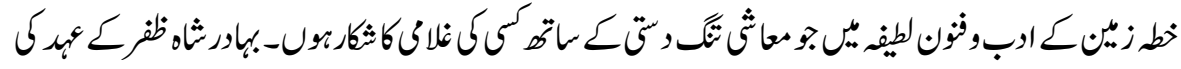

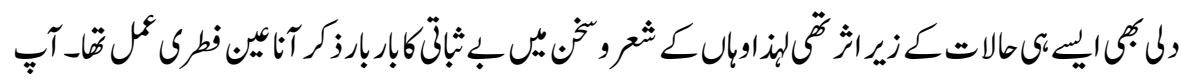

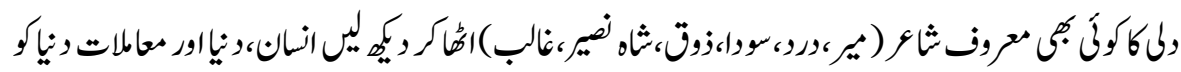

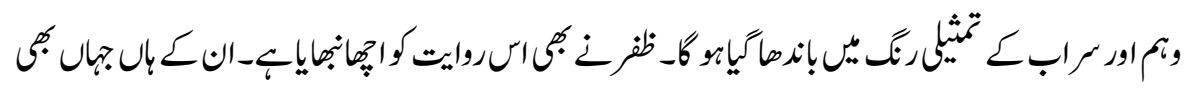

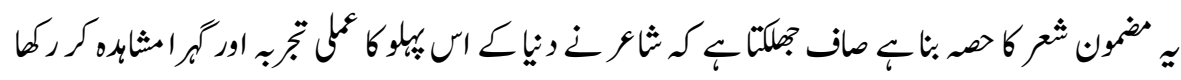

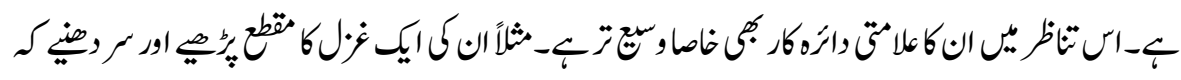

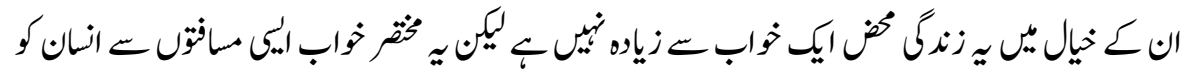




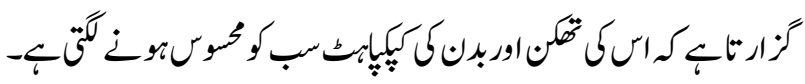

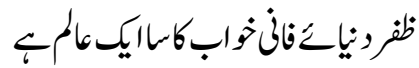

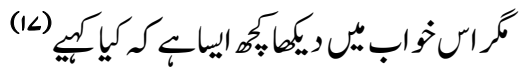

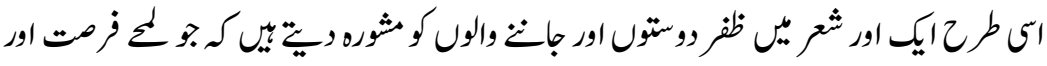

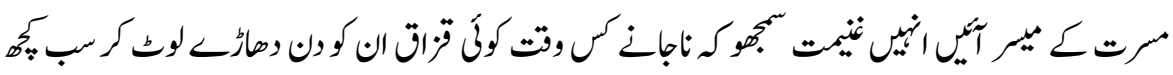

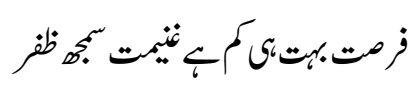

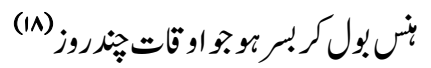

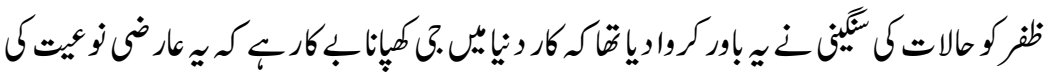

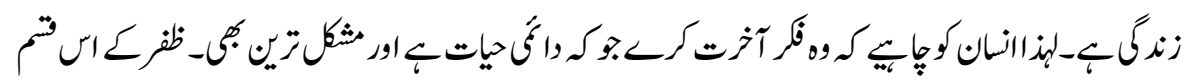

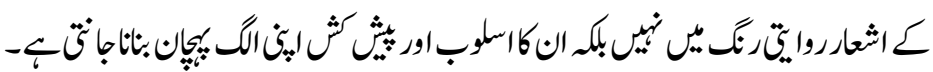

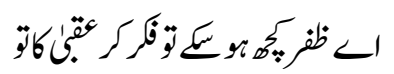

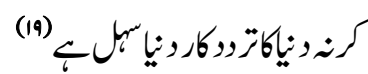

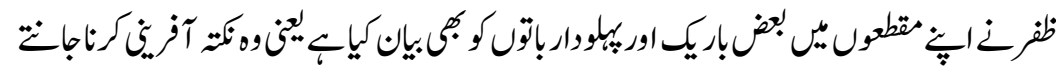

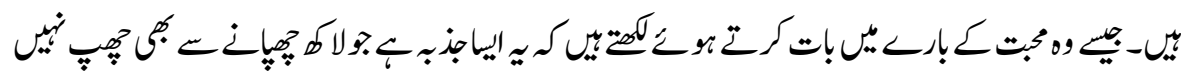

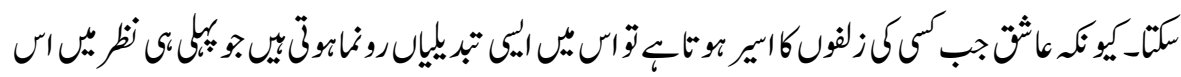

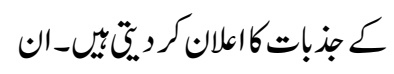

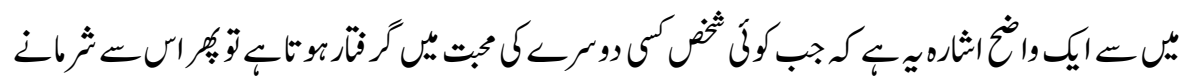

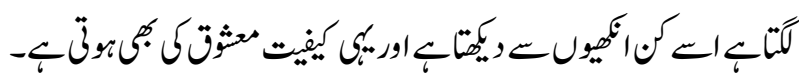

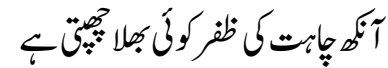

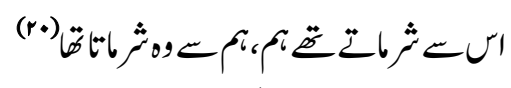

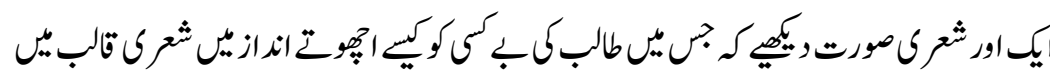

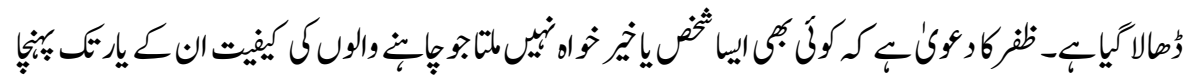




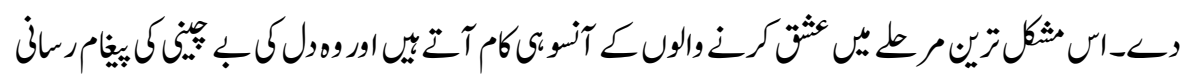

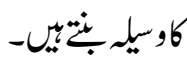

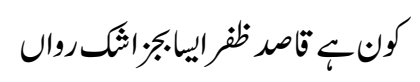

(rI)

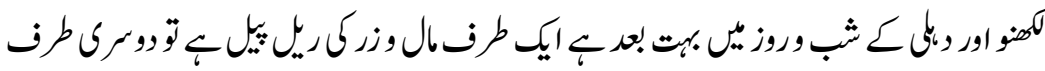

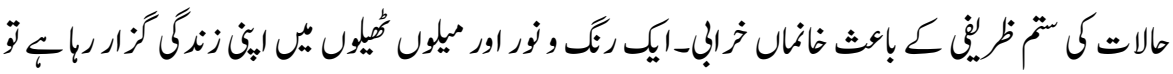

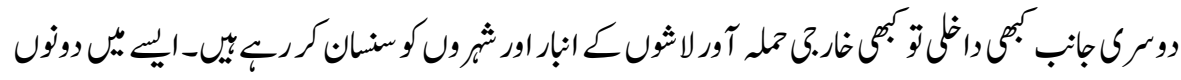

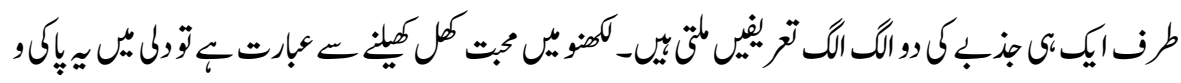

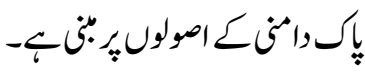

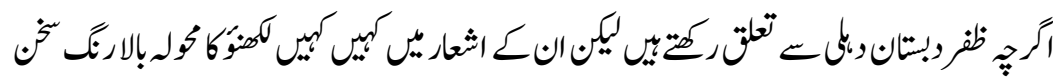

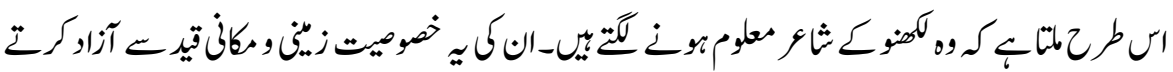

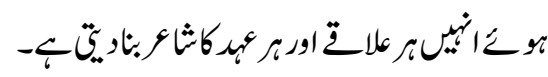

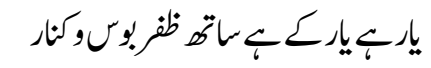

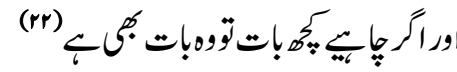

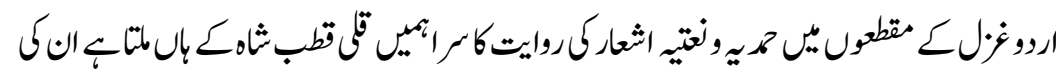

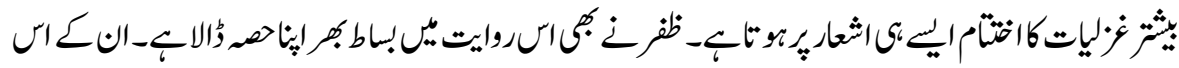

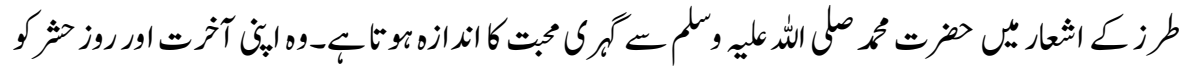

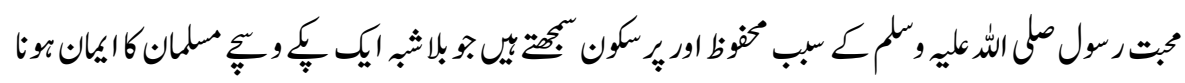
$-\sum_{-\infty}^{\infty}$

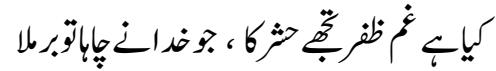
(rr)

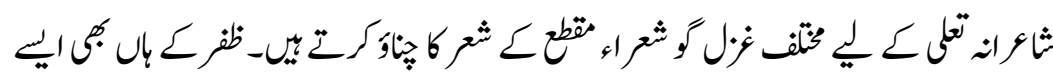

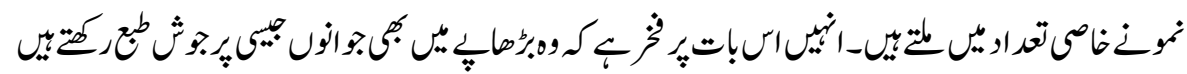




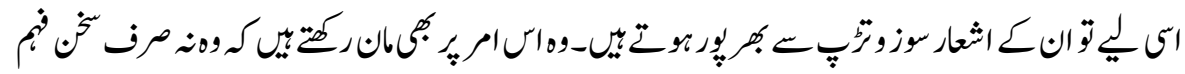

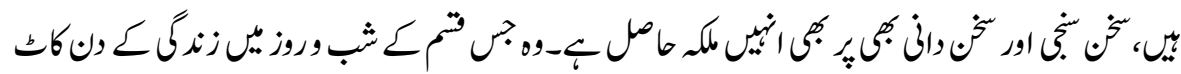

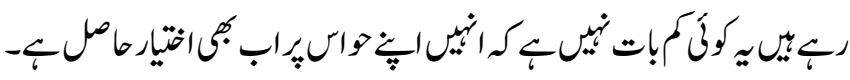

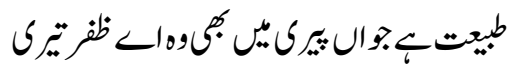

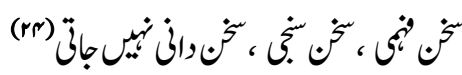

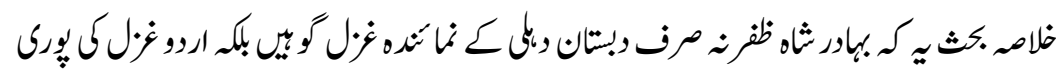

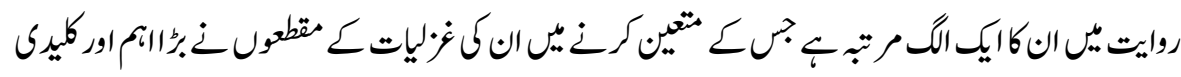
كروار لواكياب والرجات

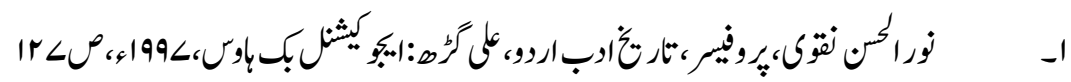

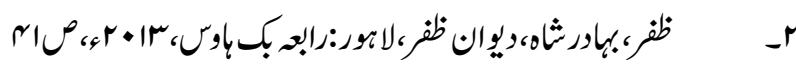
r r هـ

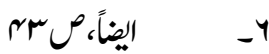

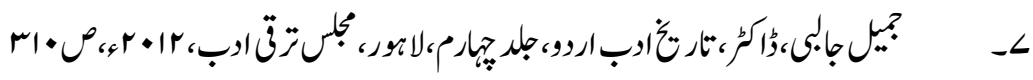

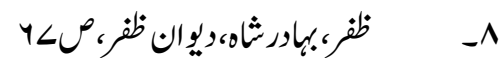

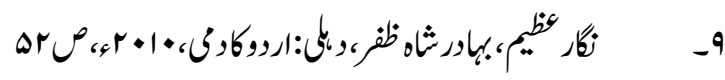

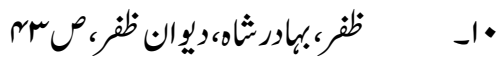

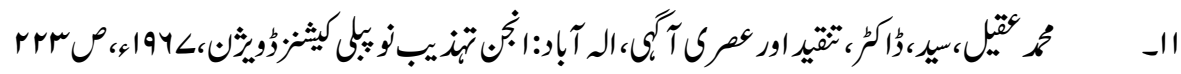

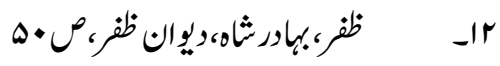
每

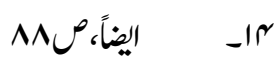


ISSN (Print): 2709-9636 | ISSN (Online): 2709-9644

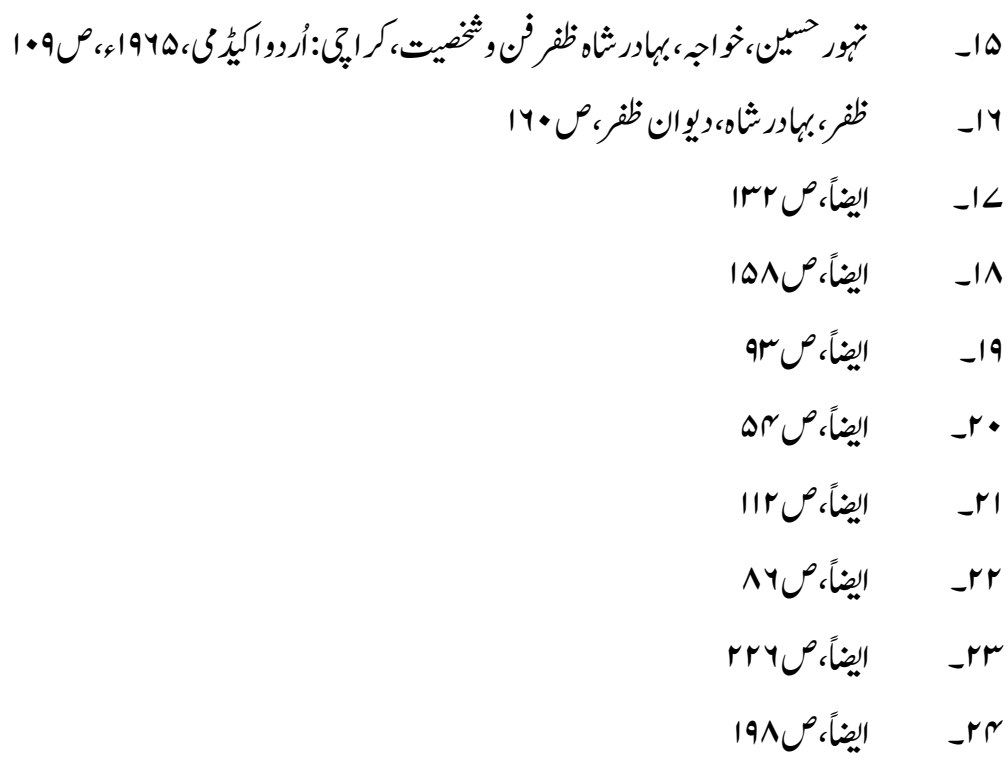

